\title{
Review
}

Neonatology

\section{Necrotizing Enterocolitis: The Mystery Goes On}

\author{
Josef $\mathrm{Neu}$ \\ Division of Neonatology, Department of Pediatrics, College of Medicine, University of Florida, Gainesville, Fla., USA
}

\section{Key Words}

Inflammation · Innate immunity $\cdot$ Microbiotica $\cdot$ Necrotizing enterocolitis · Preterm infants

\begin{abstract}
Necrotizing enterocolitis (NEC) has largely been present in neonatal intensive care units for the past 60 years. NEC prevalence has corresponded with the continued development and sophistication of neonatal intensive care. Despite major efforts towards its eradication, NEC has persisted and appears to be increasing in some centers. The pathophysiology of this disease remains poorly understood. Several issues have hampered our quest to develop a better understanding of this disease. These include the fact that what we have historically termed 'NEC' appears to be several different diseases. Animal models that are commonly used to study NEC pathophysiology and treatment do not directly reflect the most common form of the disease seen in human infants. The pathophysiology appears to be multifactorial, reflecting several different pathways to intestinal necrosis with different inciting factors. Spontaneous intestinal perforations, ischemic bowel disease secondary to cardiac anomalies as well as other entities that are clearly different from the most common form of NEC seen in preterm infants have been put into the same database. Here I describe some of the different
\end{abstract}

forms of what has been called NEC and make some comments on its pathophysiology, where available studies suggest involvement of genetic factors, intestinal immaturity, hemodynamic instability, inflammation and a dysbiotic microbial ecology. Currently utilized approaches for the diagnosis of NEC are presented and innovative technologies for the development of diagnostic and predictive biomarkers are described. Predictions for future strategies are also discussed.

(c) 2014 S. Karger AG, Basel

\section{Introduction}

Necrotizing enterocolitis (NEC) has become one of the most dreaded diseases in neonatal intensive care units. In the US and Canada, it affects approximately $7 \%$ of babies weighing between 500 and 1,500 $\mathrm{g}$ and approximately $20-30 \%$ of these babies die of this disease $[1,2]$. Survivors may be left with significant sequelae, which include not only gastrointestinal complications, such as a short gut syndrome, but also severe neurodevelopmental delay $[3,4]$. It is a very costly disease and both medical

Presented at the International Symposium 'VIIth Recent Advances in Neonatal Medicine', Würzburg, 2014.

\section{KARGER}

E-Mail karger@karger.com

www.karger.com/neo
(C) 2014 S. Karger AG, Basel

$1661-7800 / 14 / 1064-0289 \$ 39.50 / 0$
Josef Neu

Division of Neonatology, Department of Pediatrics, College of Medicine

University of Florida, Human Development Building HD 112

1600 S.W. Archer Road, Gainesville, FL 32610 (USA)

E-Mail neuj@peds.ufl.edu 
Table 1. Some of the pretenders of NEC

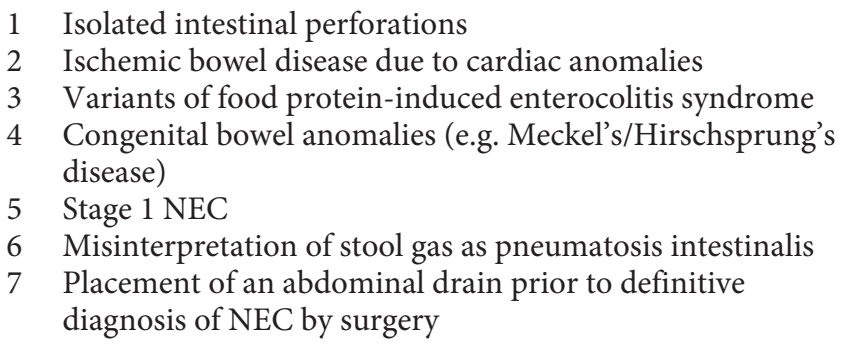

and surgical NEC markedly increase the costs of hospitalization [5]. In addition, it is a much feared disease because its putative association with enteral feeding has caused neonatologists to refrain from using the gastrointestinal tract to feed these infants and to use prolonged intravenous nutrition. This incurs its own complications, which include prolonged hospitalization, increased use of central venous catheters and increased sepsis, as well as the possibility of increasing the likely development of intestinal inflammation and damage because of gastrointestinal mucosal complications secondary to the lack of trophic stimuli.

Although considerable effort has been made to determine the pathophysiology of NEC as well as finding optimal preventative and treatment strategies, progress in eradication of this disease has been almost zero. In fact, in some countries, the incidence of NEC has actually increased most likely due to more small babies being aggressively treated and now surviving [6]. Other reasons for the lack of progress include the fact that 'NEC' is actually more than one disease. Over time, the databases of what was called NEC have included infants with ischemic bowel disease secondary to cardiac anomalies, other congenital intestinal abnormalities, such as Hirschsprung's disease, and spontaneous intestinal perforations. Table 1 lists some of these entities. Databases also have included stage I NEC [7], which is actually not a clearly defined entity. With stage 1 NEC, necrosis is implied by the name but is not validated with clear diagnostic criteria, which leads one to suspect that NEC is not yet present but may be developing. Another entity becoming increasingly recognized in older infants but with a poorly described pathophysiology, food protein-induced enterocolitis syndrome (FPIES), exhibits signs and symptoms similar to those in many preterm infants of NEC [8]. It will be critical to find ways to discern this entity from NEC since the treatment may be very different.
Another factor that has been problematic for developing better a understanding of the pathophysiology of NEC includes the lack of an animal model that directly represents the most common form of this disease. Most babies who develop NEC do not present shortly after birth in response to significant stressors, such as hypothermia, severe hypoxia and infection. However, the most commonly used animal model, which is a variant of that developed in the late 1970s, involves some variant of cold stress, infusing pathogenic bacteria such as Klebsiella, severe hypoxia and gavage feeding [9]. This is clearly not directly relevant to the disease seen in the preterm baby who typically develops NEC several weeks after birth and may have no major stress indicators prior to the onset of the disease. Piglet models have been utilized for this disease, and despite the pig gastrointestinal tract having many similarities to that of the human, piglets require their mother's colostrum or infusion of IgG to prevent death [10], whereas preterm infants do not require this for closure of the gastrointestinal tract and prevention of death. Another more recently developed model is of interest utilizing a chemical inhibitor of Paneth cells and ingestion of pathogenic Klebsiella in rodents during the later stages of pre-weaning [11]. This induces a disease similar to NEC, but fidelity of this model to the human disease remains unclear.

\section{Pathophysiology}

For the most common form of NEC in preterm infants, the etiologic factors are multifactorial and are largely related to immaturity of the gastrointestinal tract. However, the interplay of other factors, such as feeding, type of feeding, intestinal microbial ecology and the highly susceptible intestinal mucosal surface relating to inflammatory processes, all appear to play a role. Many of these have been extensively discussed in previous reviews [12-19].

Although genetic factors have been implicated by twin studies [20], only a few have suggested actual mutations that might be related to higher risk of NEC [21-24]. The innate immune system of the newborn gastrointestinal tract appears to encompass several factors that predispose to the development of this disease $[12,25]$. Furthermore, the interaction of the microbial ecosystem with this immature intestinal mucosal innate immune system appears to play a significant role $[19,26,27]$. There is a microbial ecology that differs prior to the development of NEC in these babies who subsequently develop the dis- 


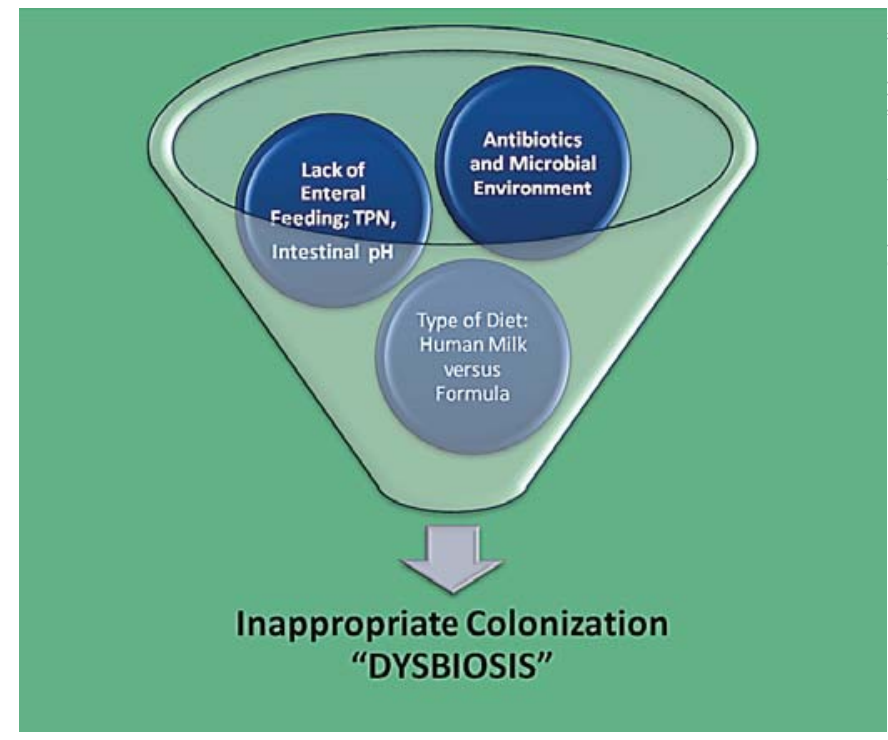

Fig. 1. Inappropriate colonization or 'dysbiosis'.

ease compared to controls [28-30]. When one evaluates the population microbes in the gastrointestinal tract prior to the development of NEC, the phylum Proteobacteria appear to be more highly represented in comparison to other phyla. Certain bacteria such as the Klebsiella genus also appear to be overrepresented prior to the development of the disease [19]. The Proteobacteria also are overrepresented prior to exacerbations of symptoms of inflammatory bowel disease in older individuals [31]. This phylum contains numerous Gram-negative pathogens with high levels of lipopolysaccharides in their cell wall.

There are several predisposing conditions that occur in neonatal intensive care that may alter the microbial ecology, especially skewing toward the Proteobacteria (fig. 1). Among these is the common practice of providing little or no food to the intestine for prolonged periods of time and nourishing the infants intravenously with total parenteral nutrition. Another is the common practice of giving antibiotics shortly after birth during a 'rule out sepsis' period [32]. Use of acid blockers and formula instead of human milk are also common practices. Proteobacteria have been found to be the dominant phylum found in rodents fed with total parenteral nutrition rather than enteral feedings [33, 34]. Mechanisms of antibiotic induced loss of colonization resistance via loss of mucin degrading capability of commensal organisms with subsequent overgrowth of pathogens similar to those found in the Proteobacteria which thrive on sialic acid residues and nitrates have also been described $[35,36]$. This phylum is responsive to the acid microclimate of the intestine with Proteobacteria growing very poorly in an acid ( $\mathrm{pH}$ 5.5) microclimate [37] and therefore may partially be related to the finding that treatment of the preterm infants with $\mathrm{H}-2$ blockers is associated with greater risk of NEC [38]. Human milk feeding is also associated with a lower intestinal $\mathrm{pH}$, but whether this is enough to affect growth of various taxa of microbiota is unclear.

Proteobacteria, which are Gram negative, have a cell wall rich in the pathogen-associated molecular pattern lipopolysaccharide, which is recognized by Toll-like receptor (TLR)4, which is developmentally regulated and is thought to play a role in the pathogenesis of the inflammation associated with the pathogenesis of NEC. These microbes may also play a role in the stimulation of certain TLR, such as TLR4, which has been implicated in the pathogenesis of NEC. The modulating effects of the adaptive immune response where $\mathrm{T}$ regulatory cells stimulate production of IL-10 and TGF- $\beta$ may also not yet be fully developed, hence allowing the proinflammatory cascade to dominate.

Secretory IgA is not released by the immature intestine in large quantities, but is found in human milk, and this may actually stimulate the development of subsequent intestinal mucosal IgA production as well as induce epithelial tight junction integrity and a decrease in intestinal permeability [39].

In addition to numerous other bioactive components that are conducive to human premature gastrointestinal tract development [40], it has been found recently that microbes present in human milk may act as commensal gastrointestinal microorganisms $[41,42]$ and potentially have beneficial effects for the developing gastrointestinal tract. The taxa from individual mother's samples over time remains similar, but each mother's samples differ from other mothers' milk microbiota [41], suggesting a specific microbial ecology for each mother-infant dyad. The site of origin of these microbes remains uncertain, but it has been speculated that because of increased permeability of the maternal intestine during pregnancy, this would be a strong possibility [43], especially since many of the taxa are shared between the milk and the maternal and infant intestine [42]. Whether these microbes play a role in the protection against NEC has not been determined, and this will be an exciting area for future research.

The concept of the enteromammary system is one that dates back to the late 1970s where studies in animals suggested that exposure of the mother to the infant can lead 
to an ingestion of the microbes that the infant is colonized with, which can lead to the development of specific humoral and cellular immune responses to those specific microbes, which can then be transmitted to the infant via breast milk [44]. This system has been somewhat understudied in human infants, but the recent finding that some (or term?) neonates that have certain infections may actually stimulate a specific immune response in the mother that modifies the breast milk immunoglobulins and immune cells is of major interest $[45,46]$. This finding supports the commonly used technique in neonatal intensive care units called kangaroo mother care [47] or skin-to-skin care, where there is close contact between mother and infant, and this could potentially have a salutary effect on the mucosal immune system of the preterm infant. All these factors may be involved in the protective effect provided by human milk to the preterm infant.

Over the past several years, the contribution of hypoxic ischemic injury to the pathogenesis of NEC has been modified [48]. It is no longer thought to be as significant as a predisposing factor as once thought. However, it is very likely that the microvasculature and blood flow in the small vessels of the intestine may be mitigated as a final component in the inflammatory cascade which results in intestinal injury [49]. Studies evaluating blood flow to the gastrointestinal tract using infrared techniques have not been very helpful in the evaluation of predisposition to development of NEC [50].

Thus, although we are beginning to put together some pieces of the pathophysiologic puzzle of NEC, there remains considerable work to be done before we have the knowledge base to confidently provide strong evidencebased strategies for NEC prevention and treatment.

\section{Diagnostic Considerations}

Several clinical factors lead to the diagnosis of NEC, including distended abdomen, peri-umbilical erythema, bloody stools, feeding intolerance and overall instability of the infant. However, these are not specific criteria. Diagnosis is usually made with abdominal radiographs with findings of pneumatosis intestinalis and/or portal venous gas [51]. Bowel wall thickening, persistent bowel loops that are filled with gas, and overall gaseous distention are suspicious signs but are not specific. Pneumoperitoneum is a sign that the intestine has perforated, but this may be due to either spontaneous intestinal perforation or NEC. The diagnosis of the pneumatosis intestinalis is some- times very difficult with various radiologists having different opinions on the same radiograph [52]. Occasionally, a neonate with a very distended abdomen and complex ascites lacks bowel gas and radiographs suggest considerable fluid in the abdominal cavity without free air. This should be highly suspicious of NEC [53]. Such a finding unfortunately often delays surgery or does not lead to operation because of lack of free air in the abdominal cavity. Approximately $50 \%$ of babies who have surgical NEC do not have free air on abdominal radiographs, but if there is fluid on ultrasonography, this should be taken very seriously as a potential surgical emergency.

At present, there are no biochemical biomarkers for NEC in clinical use that are highly specific and sensitive. C-reactive protein, white blood cell and platelet counts have been used quite commonly, but these do not specifically represent NEC if they are abnormal [54]. Biomarkers for diagnosis under study include intestinal fatty acid-binding protein, claudin 3 , calprotectin and IL-8 [54-57]. Use of these appears to be promising, but exactly how they will be utilized in the clinical setting remains to be seen.

\section{Preventative Measures}

As previously mentioned, the use of human milk is of major importance in the prevention of NEC. Baby's own mother's milk appears to confer major benefits in terms of prevention of NEC, sepsis and feeding intolerance [58]. However, neither baby's own mother's milk nor donor milk have all the nutrients required for optimal growth and development, and fortification is suggested for many of the smallest infants [59]. The provision of donor milk has been highly recommended for use in all preterm infants by the American Academy of Pediatrics [60]. However, the evidence to support widespread use of donor milk in this population remains debated.

Fear of NEC has been a major factor in neonatologists not feeding babies by the enteral route for significant periods of time and relying on total parenteral nutrition. However, over the past 2 decades several studies have suggested that using minimal enteral nutrition, which involves providing small quantities of feeding, initially usually less than $20 \mathrm{ml} / \mathrm{kg} /$ day for the first couple of days and then advancing to $20-35 \mathrm{ml} / \mathrm{kg} / \mathrm{day}$, appears to be relatively safe [61, 62]. Several neonatal intensive care units have instituted nutritional and feeding guidelines $[63,64]$, and these have been successfully utilized and actually have been shown to be efficacious in the prevention of NEC [65]. 
Other modalities which have been recommended include oral antibiotics, IgA, steroids, growth factors, antiinflammatory agents and amino acids such as arginine and glutamine $[17,66,67]$. Although some studies in animals and humans have suggested efficacy, these have not yet been sufficiently evaluated to recommend their routine use in preterm infants.

Significant controversy exists over the use of probiotics, which are defined by the World Health Organization as live microorganisms, which when administered in adequate amounts confer health benefits on the host. There are well over 100 types of probiotics with over 50 Lactobacillus species alone. There has been considerable debate on whether these should be routinely instituted for the prevention of NEC in preterm infants largely based on meta-analyses of trials done over the past 10 years [68]. Although they appear to be promising, there are still numerous safety and efficacy issues that should be addressed, and an adequately powered trial of efficacy should be completed [69-72]. Regulatory issues need to be addressed in terms of safety and efficacy if a specific probiotic is to be used to prevent diseases such as NEC. For the prevention of NEC, a probiotic would be considered by definition a pharmacologic agent and would need to undergo rigorous safety evaluation as a drug, which would provide for more reasonable quality and safety standards than if used as a food. Furthermore, use of live agents suggests the possibility of microbial mutation and possible long-term unforeseen outcomes since no longterm studies are available. Use of non-live microbial components is being studied and may represent a suitable alternative [73].

\section{Predictive Biomarkers}

If one is to use routine interventional strategies for the prevention of NEC, it would be reasonable to target babies at highest risk for development of the disease using predictive biomarkers $[57,74]$. Several studies have begun to address this and the ideal biomarker would include a bedside tool that includes a noninvasive assessment, such as urine, buccal swab, cord blood or noninvasive hemodynamic technique, such as evaluation of heart rate activity and or abdominal electrical activity or intestinal blood flow using noninvasive near-infrared techniques. Such studies are underway, but none has yet proven effective in the clinical setting for the prediction of NEC.

\section{Conclusion}

Despite considerable frustration in the progress in our understanding of NEC including its treatment and prevention, it appears that with improved definitions of the disease, improved technologies to evaluate the microbial ecology as well as the immune responses of the gastrointestinal tract and other 'omic' techniques, it is likely that new strategies will be developed that will help predict those at highest risk for this disease and additional strategies will be developed to prevent NEC in most preterm infants.

\section{Disclosure Statement}

The author discloses that he is a consultant to Infant Microbial Therapeutics and is on the Scientific Advisory Board of Medela.

\section{References}

1 Holman RC, Stoll BJ, Curns AT, Yorita KL, Steiner CA, Schonberger LB: Necrotising enterocolitis hospitalisations among neonates in the United States. Paediatr Perinat Epidemiol 2006;20:498-506.

2 Fitzgibbons SC, Ching Y, Yu D, Carpenter J, Kenny M, Weldon C, Lillehei C, Valim C, Horbar JD, Jaksic T: Mortality of necrotizing enterocolitis expressed by birth weight categories. J Pediatr Surg 2009;44:1072-1075.

- 3 Hintz SR, Kendrick DE, Stoll BJ, Vohr BR, Fanaroff AA, Donovan EF, Poole WK, Blakely ML, Wright L, Higgins R; NICHD Neonatal Research Network: Neurodevelopmental and growth outcomes of extremely low birth weight infants after necrotizing enterocolitis. Pediatrics 2005;115:696-703.
4 Martin CR, Dammann O, Allred E, Patel S, O'Shea TM, Kuban KC, Leviton A: Neurodevelopment of extremely preterm infants who had necrotizing enterocolitis with or without late bacteremia. J Pediatr 2010;157:751.e1756.e1.

5 Bisquera JA, Cooper TR, Berseth CL: Impact of necrotizing enterocolitis on length of stay and hospital charges in very low birth weight infants. Pediatrics 2002;109:423-428.

6 Ahle M, Drott P, Andersson RE: Epidemiology and trends of necrotizing enterocolitis in Sweden: 1987-2009. Pediatrics 2013;132:e443e451.
7 Bell MJ, Ternberg JL, Feigin RD, Keating JP, Marshall R, Barton L, Brotherton T: Neonatal necrotizing enterocolitis: therapeutic decisions based upon clinical staging. Ann Surg 1978;187:1-6.

-8 Feuille E, Nowak-Wegrzyn A: Definition, etiology, and diagnosis of food protein-induced enterocolitis syndrome. Curr Opin Allergy Clin Immunol 2014;14:222-228.

-9 Pitt J, Barlow B, Heird WC: Protection against experimental necrotizing enterocolitis by maternal milk. I. Role of milk leukocytes. Pediatr Res 1977;11:906-909.

10 Devillers N, Le Dividich J, Prunier A: Influence of colostrum intake on piglet survival and immunity. Animal 2011;5:1605-1612. 
-11 McElroy SJ, Underwood MA, Sherman MP: Paneth cells and necrotizing enterocolitis: a novel hypothesis for disease pathogenesis. Neonatology 2013;103:10-20.

$\checkmark 12$ Neu J, Walker WA: Necrotizing enterocolitis. N Engl J Med 2011;364:255-264.

13 Murgas Torrazza R, Neu J: The developing intestinal microbiome and its relationship to health and disease in the neonate. J Perinatol 2011;31:S29-S34.

14 Sharma R, Hudak ML: A clinical perspective of necrotizing enterocolitis: past, present, and future. Clin Perinatol 2013;40:27-51.

$\checkmark 15$ Sharma R, Young C, Neu J: Molecular modulation of intestinal epithelial barrier: contribution of microbiota. J Biomed Biotechnol 2010;2010:305879.

-16 Lin PW, Stoll BJ: Necrotising enterocolitis. Lancet 2006;368:1271-1283.

$\checkmark 17$ Kasivajjula H, Maheshwari A: Pathophysiology and current management of necrotizing enterocolitis. Indian J Pediatr 2014;81:489497.

18 Gordon PV, Swanson JR: Necrotizing enterocolitis is one disease with many origins and potential means of prevention. Pathophysiology 2014;21:13-19.

19 Torrazza RM, Li N, Neu J: Decoding the enigma of necrotizing enterocolitis in premature infants. Pathophysiology 2014;21:21-27.

20 Bhandari V, Bizzarro MJ, Shetty A, Zhong X, Page GP, Zhang H, Ment LR, Gruen JR; Neonatal Genetics Study Group: Familial and genetic susceptibility to major neonatal morbidities in preterm twins. Pediatrics 2006;117: 1901-1906.

-21 Treszl A, Heninger E, Kalman A, Schuler A, Tulassay T, Vasarhelyi B: Lower prevalence of IL-4 receptor alpha-chain gene $G$ variant in very-low-birth-weight infants with necrotizing enterocolitis. J Pediatr Surg 2003;38: 1374-1378.

22 Szebeni B, Szekeres R, Rusai K, Vannay A, Veres G, Treszl A, Arato A, Tulassay T, Vasarhelyi B: Genetic polymorphisms of CD14, toll-like receptor 4 , and caspase-recruitment domain 15 are not associated with necrotizing enterocolitis in very low birth weight infants. J Pediatr Gastroenterol Nutr 2006;42:27-31.

-23 Moonen RM, Paulussen AD, Souren NY, Kessels AG, Rubio-Gozalbo ME, Villamor E: Carbamoyl phosphate synthetase polymorphisms as a risk factor for necrotizing enterocolitis. Pediatr Res 2007;62:188-190.

-24 Sampath V, Le M, Lane L, Patel AL, Cohen JD, Simpson PM, Garland JS, Hines RN: The NFKB1 (g.-24519delATTG) variant is associated with necrotizing enterocolitis (NEC) in premature infants. J Surg Res 2011;169:e51e57.

25 Hackam DJ, Afrazi A, Good M, Sodhi CP: Innate immune signaling in the pathogenesis of necrotizing enterocolitis. Clin Dev Immunol 2013;2013:475415.
26 Claud EC, Walker WA: Hypothesis: inappropriate colonization of the premature intestine can cause neonatal necrotizing enterocolitis. Faseb J 2001;15:1398-1403.

27 Lin PW, Stoll BJ: Necrotising enterocolitis. Lancet 2006;368:1271-1283.

28 Mai V, Torrazza RM, Ukhanova M, Wang X, Sun Y, Li N, Shuster J, Sharma R, Hudak ML, Neu J: Distortions in development of intestinal microbiota associated with late onset sepsis in preterm infants. PLoS One 2013; 8:e52876.

29 Wang Y, Hoenig JD, Malin KJ, Qamar S, Petrof EO, Sun J, Antonopoulos DA, Chang EB, Claud EC: 16 S rRNA gene-based analysis of fecal microbiota from preterm infants with and without necrotizing enterocolitis. ISME J 2009;3:944-954.

- 30 Morrow AL, Lagomarcino AJ, Schibler KR, Taft DH, Yu Z, Wang B, Altaye M, Wagner M, Gevers D, Ward DV, Kennedy MA, Huttenhower C, Newburg DS: Early microbial and metabolomic signatures predict later onset of necrotizing enterocolitis in preterm infants. Microbiome 2013;1:13

31 Li Q, Wang C, Tang C, Li N, Li J: Molecularphylogenetic characterization of the microbiota in ulcerated and non-ulcerated regions in the patients with Crohn's disease. PLoS One 2012;7:e34939.

32 Clark RH, Bloom BT, Spitzer AR, Gerstmann DR: Reported medication use in the neonatal intensive care unit: data from a large national data set. Pediatrics 2006;117:1979-1987.

33 Miyasaka EA, Feng Y, Poroyko V, Falkowski NR, Erb-Downward J, Gillilland MG 3rd, Mason KL, Huffnagle GB, Teitelbaum DH: Total parenteral nutrition-associated lamina propria inflammation in mice is mediated by a MyD88-dependent mechanism. J Immunol 2013;190:6607-6615.

-34 Demehri FR, Barrett M, Ralls MW, Miyasaka EA, Feng Y, Teitelbaum DH: Intestinal epithelial cell apoptosis and loss of barrier function in the setting of altered microbiota with enteral nutrient deprivation. Frontiers in Cellular and Infection Microbiology 2013;3:105.

35 Stecher B: Finding a sugary foothold: how antibiotics pave the way for enteric pathogens. Cell Host Microbe 2013;14:225-227.

-36 Ng KM, Ferreyra JA, Higginbottom SK, Lynch JB, Kashyap PC, Gopinath S, Naidu N, Choudhury B, Weimer BC, Monack DM: Microbiota-liberated host sugars facilitate postantibiotic expansion of enteric pathogens. Nature 2013;502:96-99.

37 Duncan SH, Louis P, Thomson JM, Flint HJ: The role of $\mathrm{pH}$ in determining the species composition of the human colonic microbiota. Environl Microbiol 2009;11:2112-2122.

8 Chung EY, Yardley J: Are there risks associated with empiric acid suppression treatment of infants and children suspected of having gastroesophageal reflux disease? Hosp Pediatr 2013;3:16-23.
39 Rogier EW, Frantz AL, Bruno ME, Wedlund L, Cohen DA, Stromberg AJ, Kaetzel CS: Secretory antibodies in breast milk promote longterm intestinal homeostasis by regulating the gut microbiota and host gene expression. Proc Natl Acad Sci USA 2014;111:3074-3079.

40 Neu J, Mihatsch WA, Zegarra J, Supapannachart S, Ding ZY, Murguia-Peniche T: Intestinal mucosal defense system. Part 1. Consensus recommendations for immunonutrients. J Pediatr 2013;162:S56-S63.

41 Hunt KM, Foster JA, Forney LJ, Schutte UM, Beck DL, Abdo Z, Fox LK, Williams JE, McGuire MK, McGuire MA: Characterization of the diversity and temporal stability of bacterial communities in human milk. PLoS One 2011;6:e21313.

- 42 Ward TL, Hosid S, Ioshikhes I, Altosaar I: Human milk metagenome: a functional capacity analysis. BMC Microbiol 2013;13:116.

43 Jeurink PV, van Bergenhenegouwen J, Jimenez E, Knippels LM, Fernandez L, Garssen J, Knol J, Rodriguez JM, Martin R: Human milk: a source of more life than we imagine. Benef Microbes 2013;4:17-30.

44 Kleinman RE, Walker WA: The enteromammary immune system: an important new concept in breast milk host defense. Dig Dis Sci 1979;24:876-882.

45 Riskin A, Almog M, Peri R, Halasz K, Srugo I, Kessel A: Changes in immunomodulatory constituents of human milk in response to active infection in the nursing infant. Pediatr Res 2012;71:220-225.

46 Neu J, Sullivan S: Baby and breast: a dynamic interaction. Pediatr Res 2012;71:135.

47 Dodd VL: Implications of kangaroo care for growth and development in preterm infants. J Obstet Gynecol Neonatal Nurs 2005;34: 218-232.

48 Neu J: The 'myth' of asphyxia and hypoxiaischemia as primary causes of necrotizing enterocolitis. Biol Neonate 2005;87:97-98.

49 Young CM, Kingma SD, Neu J: Ischemia-reperfusion and neonatal intestinal injury. J Pediatr 2011;158:e25-e28.

50 Cerbo RM, Maragliano R, Pozzi M, Strocchio L, Mostert M, Manzoni P, Stronati M: Global perfusion assessment and tissue oxygen saturation in preterm infants: where are we? Early Hum Dev 2013;89:S44-S46.

51 Hollingsworth CL, Rice HE: The Duke Abdominal Assessment Scale: initial experience. Expert Rev Gastroenterol Hepatol 2010;4: 569-574.

52 Rehan VK, Seshia MM, Johnston B, Reed M, Wilmot $\mathrm{D}$, Cook V: Observer variability in interpretation of abdominal radiographs of infants with suspected necrotizing enterocolitis Clin Pediatr 1999;38:637-643.

53 McBride WJ, Roy S, Brudnicki A, Stringel G: Correlation of complex ascites with intestinal gangrene and perforation in neonates with necrotizing enterocolitis. J Pediatr Surg 2010; 45:887-889. 
54 Thuijls G, Derikx JP, van Wijck K, Zimmermann LJ, Degraeuwe PL, Mulder TL, Van der Zee DC, Brouwers HA, Verhoeven BH, van Heurn LW: Non-invasive markers for early diagnosis and determination of the severity of necrotizing enterocolitis. Ann Surg 2010;251: 1174-1180.

$55 \mathrm{Ng}$ EW, Poon TC, Lam HS, Cheung HM, Ma TP, Chan KY, Wong RP, Leung KT, Lam MM, Li K: Gut-associated biomarkers LFABP, I-FABP, and TFF3 and LIT score for diagnosis of surgical necrotizing enterocolitis in preterm infants. Ann Surg 2013;258:11111118.

56 Benkoe T, Reck C, Pones M, Weninger M, Gleiss A, Stift A, Rebhandl W: Interleukin-8 predicts 60 -day mortality in premature infants with necrotizing enterocolitis. J Pediatr Surg 2014;49:385-389.

57 Young C, Sharma R, Handfield M, Mai V, Neu J: Biomarkers for infants at risk for necrotizing enterocolitis: clues to prevention? Pediatr Res 2009;65:91R-97R.

58 Menon G, Williams TC: Human milk for preterm infants: why, what, when and how? Arch Dis Child Fetal Neonatal Ed 2013;98:F559F562.
59 Arslanoglu S, Corpeleijn W, Moro G, Braegger C, Campoy C, Colomb V, Decsi T, Domellof M, Fewtrell M, Hojsak I: Donor Human Milk for Preterm Infants: Current Evidence and Research Directions. J Pediatr Gastroenterol Nutr 2013;57:535-542.

60 Burton OM: The American Academy of Pediatrics and breastfeeding. Breastfeed Med 2012;7:334-336.

61 Ramani M, Ambalavanan N: Feeding practices and necrotizing enterocolitis. Clin Perinatol 2013;40:1-10.

62 Hay WW Jr: Strategies for feeding the preterm infant. Neonatology 2008;94:245-254.

63 Torrazza RM, Neu J: Evidence-Based Guidelines for Optimization of Nutrition for the Very Low Birthweight Infant. NeoReviews 2013;14:e340-e349.

64 Parker LA, Neu J, Torrazza RM, Li Y: Scientifically Based Strategies for Enteral Feeding in Premature Infants. NeoReviews 2013; 14:e350-e359.

65 Gephart SM, Hanson CK: Preventing necrotizing enterocolitis with standardized feeding protocols: not only possible, but imperative. Adv Neonatal Care 2013;13:48-54.

-66 Morgan JA, Young L, McGuire W: Pathogenesis and prevention of necrotizing enterocolitis. Curr Opin Infect Dis 2011;24:183-189.

67 Neu J, Walker WA: Necrotizing enterocolitis. N Engl J Med 2011;364:255-264.
68 Deshpande G, Rao S, Patole S, Bulsara M: Updated Meta-analysis of Probiotics for Preventing Necrotizing Enterocolitis in Preterm Neonates. Pediatrics 2010;125:921-930.

69 Modi N: Probiotics and Necrotising Enterocolitis: the devil (as always) is in the detail. Commentary on N. Ofek Shlomai et al: Probiotics for preterm neonates: what will it take to change clinical practice? (Neonatology 2014; 105:64-70). Neonatology 2014;105:71-73.

70 Neu J: Routine Probiotics for Premature Infants: Let's Be Careful! J Pediatr 2011;158: 672-674.

71 Claud EC: First do no harm. J Pediatr Pharmacol Ther 2012;17:298-301.

72 Martin CR: Probiotics for the prevention of necrotizing enterocolitis: not just which ones but also why? J Pediatr Gastroenterol Nutr 2013;57:3.

73 Kataria J, Li N, Wynn JL, Neu J: Probiotic microbes: do they need to be alive to be beneficial? Nutr Rev 2009;67:546-550.

74 Murgas Torrazza R, Li N, Young C, Kobeissy F, Chow M, Chen S, Mai V, Sharma R, Hudak M, Shuster J, Neu J: Pilot study using proteomics to identify predictive biomarkers of necrotizing enterocolitis from buccal swabs in very low birth weight infants. Neonatology 2013;104:234-242. 